\title{
Sobre los espacios en La dama duende: el cuarto de don Manuel*
}

\author{
Marc Vits e \\ Universidad de Toulouse-Le Mirail
}

No hay comedia de capa y espada de Calderón más célebre y, al parecer, mejor conocida que la escrita en 1629 por este dramalurgo y titulada La dama duende. No obstante, una mera ojeada sobre la labor crítica a ella referida no tarda en revelar la existencia ineludible de una importante serie de problemas harto difíciles, y por eso dejados, en su mayoría, sin resolver. Entre ellos, los que piden más urgente revisión son los que se podrían tlamar los problemas textuales, expresión que se ha de entender en un doble, y complementario sentido: en el sentido bibliografico y filologico primero; y, luego, en el sentido de la interpretación correcta de las informaciones proporcionadas por el texto mismo sobre los aspectos espaciales, dramáticos y escénicos, de una comedia en la que, como se sabe, desempeña un papel fundamental la disposición topográfica de la casa del amigo de don Manuel, don Juan de Toledo.

Estamos lejos, en efecto, de poseer una edjción crítica fidedigna de $L a$ dama duende. Y esto, no solamente porque las varias ediciones llevadas a cabo por Ángel Valbuena Briones son malas (como la preparada para los Clásicos castellanos, núm. 137) o malísimas (como la preparada en 1976 para la 
colección Letras hispánicas, núm. 39)', sino también porque ninguna de las hasta ahora elaboradas, por éste u otros cstudiosos, luvo en cuenta los textos no autorizados salidos a luz en Valencia y en Zaragoza en 1636, es decir en el mismo año que la publicación de la Primera parte de Madrid.

No es necesario, para el tema escogido hoy, entrar en el detalle de esta maraña bibliográfica. Será suficiente indicar que los dos textos no madrileños parecen constituir una primera verșión de la comedia y que su tercera jornada —publicada en el número 21 de Criticón, 1983, pp. 49-91—, totalmente diferente de la oficial de la Primera parte, permite solucionar algunos de los enigmas hasta ahora no percibidos, o no explicados, por la crítica. A ello volveremos en el curso de nuestro análisis del espacio en La dama duende.

Antes de abordarlo directamente, sin embargo, importa dar algunas precisiones terminologicas, tanto para conferir mayor claridad a la exposición, como para llegar a unas conclusiones metodologicas más pertinentes, si es que de nuestra demostración se puedan sacar algunas. Se trata de la definicion de las nociones de espacio dramático y de espacio escénico?

Por espacio dramático se entenderá el espacio de la ficción, el espacio representado o significado en el tex to escrito, es decir los lugares por los que se mueven los entes de ficción que son los personajes: aquí, por ejemplo, la casa de don Juan, en el Madrid de 1629, capital de la España del joven Felipe IV, padre del recién nacido Baltasar Carlos, etc. Este espacio dramático, en su esencia, sólo puede visualizarse en el metalenguaje del crítico o del espectador, que lo van construyendo imaginariamente a partir de las informaciones proporcionadas sobre su universo por unos personajes cuyo marco de evolución y de acción hay que fijar.

E) espacio escénico, en/cambio, designará el espacio concretamente perceptible por el público en el escenario peculiar de tal o cual función teatral. Espacio material representante o significante de una u otra de las virtualidades del espacio dramático, dependerá, para cada una de sus realizaciones circunstanciales, de las condiciones escenográficas ofrecidas a la labor del «autor» o director de escena y de la interpretación por éste de las

- Este trabajo se publico en Noras y estudios filofogicos, 2, 1985. pp. 7-32. Lo reproducimos aquí por Ia poca difusión que tuvo aquel volumen de $N E F$ y por el interés que creemos tiene el estudio de Vitse (nota de los editores).

l Nos valdrernos de esta cdición, sin embargo, para nuestras citas, porque es la más corriente y la única en tener una numeración continua, y no por jornada, de los versos.

2 Véanse las definiciones -aquí libremente adaptadas- del Dictionnaire du theatre, de Patrice Pavis, Paris, Editions Sociales, 1980, pp. 15I-59. 
indicaciones incluidas en el texto escrito, tanto en el texto principal (el que dicen los personajes) como en el texto secundario (las acotaciones).

$Y$ ahora, a la luz de estas previas y muy elementales definiciones, y con la ayuda del gran calderonista J. E. Varey - su ponencia en el congreso de Calderón de Madrid, en 198$]^{3}$, versaba sobre el mismo tema, y será para nosotros motivo para un diálogo a la vez agradecido y crítico-, tratemos de descubrir algunos de los aspectos constitutivos del espacio en La dama duende, y particularmente todo lo que concierne al cuarto de don Manuel.

Este cuarto, en efecto, aparece como el elemento clave del complicadísimo espacio doméstico formado por la casa aristocrática del huésped de don Manuel y hemano mayor de doña Ángela y de don Luis. A este bloque espacial -cuarto se ha de entender en su significación áusea de "parte de la casa destinada a alguna persona con su familia» (Aut), o sea algo comparable con los appartements de las piezas de Coneille o Racine, o con to que hoy, en los hoteles, se suele llamar una suite-, a este conjunto de habitaciones, pues, tenemos una primera alusión en el parlamento dirigido a Luis por su criado y confidente Rodrigo, cuando le revcla éste las precauciones tomadas por el mayorazgo don Juan para asslar el aposento de su invitado e impedir cualquier comunicación directa desde su cuarto hacia el interior de la casa:

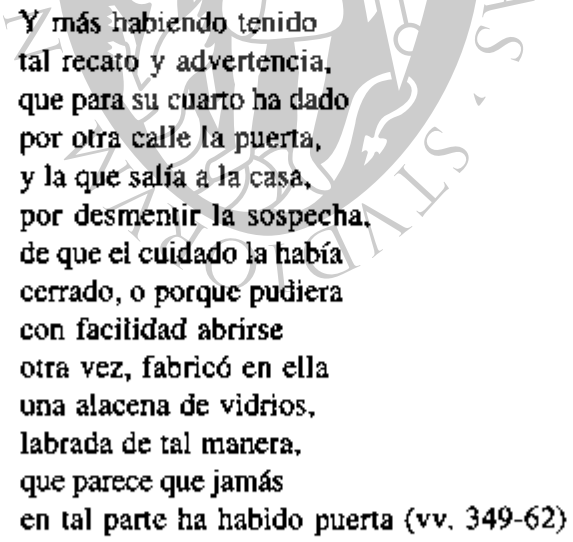

3 aLa dama duende de Calderón: símbolos y escenografia», en Calderón. Actas del Congreso Internacional sobre Calderon y el teatro espanol del Sigio de Oro, (Madrid. 1981), Madrid, C.S.I.C., 1983, tomo 1, pp. 165-83 (Anejos de la revista Segismundo, 6). 
Estos versos no dejan lugar a dudas. Contrariamente a lo que a veces se sostiene ${ }^{4}$, el que ha sido modificado por don Juan no es el cuarto de doña Ángela, sino el de don Manuel ( «su cuarto», v, $35 \mathrm{I}=\mathrm{el}$ de don Manuel). La transformación no ha consistido en abrit una nueva puerta hacia el exterior, es decir hacia otra calle que la de la puerta principal de la casa: lo que se ha hecho es ocultar con una alacena la hoja interior (la que mira hacia dentro) de la puerta interior (la que da hacia la casa y no a la calle) que existía en el cuarto de don Manuel, de modo que éste quede persuadido de que el único acceso a su aposento lo constituye la puerta lateral o secundaria mencionada en el texto: «para su cuarto ha dado / por otra calle la puerta» (vv. 351-352).

En el núcleo escénico posterior, Ángela y su criada discuten sobre unos acontecimientos inmediatamente anteriores, y su conversación nos trae gran acopio de infornaciones sobre el punto que nos interesa. Conviene citar gran parte de este dílogo:

ISABEL

DOÑA ÁNGELA

ISABEL

DON̄A ANGELA

ISABEl.

DOÑA ÁNGELA

\section{Y si para eso}

te dispones, yo bien sé por dónde verle podrás. y aún más que velle.

Tú estás

toca ¿Cómo, si se ve de mi cuarto tan distante, el suyo?

Parte hay por donde

este cuarto corresponde al otro; esto no te espante.

No porque verlo deseo. sino solo por saber,

dime, ¿como puede ser? que lo escucho y no lo creo. ¿No has ofdo que labró en la puerta una alacena to hermano?

Ya lo que ordena tu ingenio he entendido yo. Dirás que pues es de tabla.

4 Varey, art. cit., p. 169: «El cuarto de Doña Ángela ha sido modificado, tapando la puerta que daba à resto de la casa por una alacena, y abriendo en él una nueva pueria que da a otra callew. 


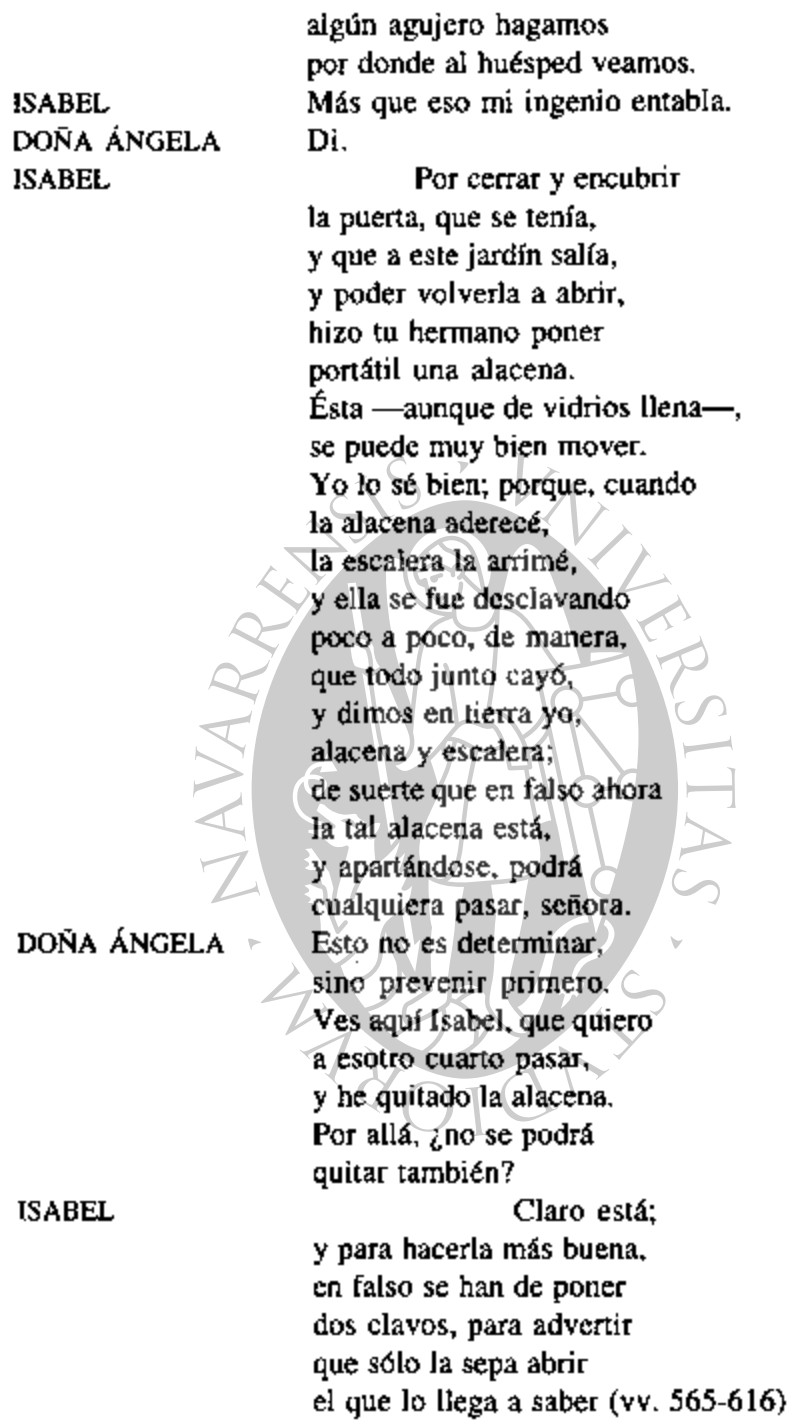

¿De qué nos enteramos aquí? Esencialmente, de que cl cuarto de Ángela se encuentra a mucha distancia del de don Manuel ( $\alpha$ si se ve / de mi cuarto tan distante / el suyo», vv. 568-70). A pesar de las afirmaciones repetidas de J. E. 
Varey (pp. $170171,172,175,180$ ), los dos aposentos no son contiguos. $Y$ este hecho, basado en la declaración, de por sí fehaciente, de quien ha de conocer perfectamente la disposición de su propia casa, recibe renovadas confirmaciones en el posterior desartollo de la comedia. Hay, en primer lugar, la aseveración de Isabel, que precisa (vv. 585-88) que la puerta modificada por don Juan en el cuarto de Manuel no da al cuarto de Ángela, sino a un «jardín», Este jardín interior de la casa —que no se volverâ a mencionar- se sitúa pues en algún trozo del canino que conduce del cuarto de Ángela, en que probablemente se desarrolla ta escena que estudiamos ${ }^{5}$, hasta el cuano de Manuel, y constifuye por consiguiente un elemento de la parte

$$
\text { por donde }
$$

este cuarto [en que están Isabel y Ángela] corresponde al otro [el de Manuel] (vv. 570-72)

Este «paso» -así se llama en las versiones no oficiales ${ }^{6}$ - se configura, además, como un espacio abierto 0 , por lo menos, como un espacio ofrecido a la mirada de los habituales moradores de la casa, ya que, para utilizarlo en sus andanzas burladoras, la protagonista está obligada a tomar un sinnúmero

5 Probablemente, decimos, porque si no hay nada en el texto que lo impida, no hay nada tampoco que permita afirmarlo tajantemente. Por otra pane, dudamos mucho de que los núcleos escénicos $D^{\prime}$ y $F$ (véase infra la columna derecha del cuadro) se desarrollen efectivamente en el cuarto de Ángela. Este, si damos fe al texto, es un cuarto aislado o, por lo menos, no accesible a los huéspedes que no deben conocer la presencia de Ángeia, viuda con deudas, en casa de sus hermanos. El espacio dramático $D^{\prime}$ y $F$, innominado, no parece corresponder al espacio cerrado que sirve de ećrcels a la joven y tramoyera viluda: cruzan por él casi todos los personajes (incluso el propio Manuel, a quien Rodrigo divisa desde lejos. vv. 1401-2), de modo que podta tratarse de la ssalan, en el sentido que da al vocablo el Diccionario de Autoridades: «La pieza principal de la casa, o cuano donde se vive, y donde se recibun las visitas de cumplimiento, o se tratan los negocios. Dijose sala porque se sale a ellu de otros cuartos secretos...». Por otra parte, no implica ninguna contradicción el que Ángela pueda decir, en los versos 607-9: «Ves aqui, Isabel, que quiero / a esotro cuarto pasar / y he quitado la ajacena». Al pronunciar estas pababras, no aquila» efectivamente una alacena que no se encuentra sino en el cuarto de Mantei. Lo que hace es inventar una hipótesis: 'Supon, Isabel, que yo, llevada del deseo de penetrar en el cuarto de Manuel, haya llegado frente a la alacena y la haya quitado'. Para otra equivalencia entre "ves üjui» y 'suponn', véanse los versos 1067-71, con idéntica elaboración de una conjetura por Cosme: "Ves aquí que van y vienen / papeles y que jamás, $/$ aunque los examines más / ciertos desengaĭos tienen: / iqué crecerás?».

6 Criticón, 21, 1983, p. 75, vv, 478-80: $\propto$ y te escondes $f$ por esle paso que tienes $t$ oculto para si cuarto...\%. 
de precauciones. Asf es como le es preciso, antes de arriesgarse a atravesarlo, esperar la salida o el sueño de sus hemanos (vv. 1765-66; 1802; 1985-88), o bien disimular la luz en una «linterna cubierta» («porque de aquesta manera / no se viera”, vv. 2004-05).

En segundo lugar, son pruebas indiscutibles de la distancia que media entre los dos cuartos las cantidades de versos que se pronuncian entre el momento de la salida de los personajes del uno y el momento de su entrada en el otro. Cuando mejor se miden estos intervalos temporales de uлa duración media de unos 40 versos - y que nada justificaría desde el punto de vista del tempo dramático, en caso de contiguiidad efectiva de los dos bloques espaciales - es cuando se escenifican en la tercera jornada los acelerados vaivenes provocados por las inesperadas intervenciones de don Juan y don Luis en la fiesta nocturna organizada por su enamorada hermana. Un rápido recuento da los resultados siguientes. Se pronuncian

- 40 versos (vv, 2439-78) durante el víaje que Manuel, guiado por Isabel, hace desde el cuarto de Ángela hasta "aquel cuarto [...] apartado" (vv. 2433-34), del que él no sabe que es su propio aposento.

-77 versos ( $v v .2484-2560$ ), o sea poco más de dos veces 38 versos, mientras ocure el rcgreso de la criada hacia el cuarto de su ana y su nueva ida al cuarto del huésped, ahora libre de! peligto que representaba don Juan.

- 29 versos ( $v$ v. 2575-2603) - a los que hay que añadir el tiempo indeterminado que separa el final del monólogo de Manuel (v. 2592) de la vuelta al escenario de Ángela y de sus mujeres - que corresponden a los minutos necesarios para que Isabel lleve a Cosme desde el cuarto de su amo hasta la «cuadra» ocupada por Ángela.

- Y, por fin, 50 versos (vv. 2677-2728), para el recorrido del mismo itinerario, pero en sentido contrario.

Resumiendo: la ubicación de la alacena en la hoja interior de la puerta interior del cuarto de Manuel y la distancia incomprimible entre su aposento y el de la misteriosa dama son las dos conclusiones, al parecer incuestionables, que imponen las evidencias textuales. Apenas, sin embargo, quedan establecidas estas verdades, cuando otra evidencia textual obliga a poner las primeras en tela de juicio. Es la que se encuentra, también en la tercera jornada, en el momento del último recorrido dado entre los dos aposentos mencionados y causado por la sospecha que tiene don Luis de la anormal presencia de unas personas no identificadas en el cuarto de su tan vigilada hermana. Leamos el texio ( $v v, 2696-2732)$ en la edición de Á. Valbuena Briones, sacada, como cl conjunto de la comedia de la Primera parte 
madrileña. Los personajes se encuentran, sin que haya la menor duda en ello, en el cuarto de Ángela:

DOÑA ANGELA

DON LUIS

DON̄A ÁNGELA

DON LUIS

¿Para qué informarte quieres de lo que, en estando a solas, se entretienen las mujeres?

(Hacen ruido en Ia alacena Isabel y Cosme)

Y aquel ruido, $i q u e ́$ es?

(iYo muero!)

¿Vive Dios, que allíanda gente!

Ya no puede ser mi hermano

quien se guarda de esta suerte.

(Aparta la alacena para entrar con luz)

¿Ay de mí! ;Cielos piadosos

que queriendo neciamente estorbar aquí los celos. que amor en mi pecho enciende, celos de honor averiguo! Luz tomare, aunque imprudente, pues todo se halla con luz, y el honor con luz se pierde. (Vase)

DOÑA ÁNGELA AAy, Beatriz, perdidas somos, si le topa?

DOÑA BEATRIZ

Si le tiene

en su cuarto ya Isabel, en vano dudas y temes, pues te asegura el secreto de kalacena.

DOÑA ÁNGELA

DOÑA BEATRIZ $Y_{i \text { si fuese }}$

tal mi desdicha, que all, con la turbación, no hubiese cerrado bien Isabel, y él entrase allá?

DOÑA ÁNGELA en salvo será importante. De tu padre ires a valerme como b́l se valio de mí; porque trocadas las suertes, 
si a ti te trujo un pesar. a ml otro pesar me lleve.

(Vanse y salen por el alacena Isabel y Cosme y por otra parte don Manuel)

ISABEL

DON MANUEL
Entra presto. (Vase)

Ya otra vez

en la cuadra siento gente.

(Sale don Luis con Iuz)

Yo vi un hombre jvive Dios!

Malo es esto.
DON LUIS

COSME

DON LUIS
¿Cómo tienen

desviada esta alacena? (vv. 2696-2732)

Si tenemos que dar fe a la literalidad de estos versos nos es forzoso comprobar, primeto, que la alacena se encuentra en una de las puertas del cuarto de Ángela, ya que don Luis está obligado a apartarla para emprender la persecución de los desconocidos intrusos amenazadores de su honor; y, luego, y por consiguiente, que el cuarto de Manuel ocupa una posición de relativa contigüidad con relación al de Ángela, Jo que justificaría la cifra notablemente reducida de los versos pronunciados —unos 18 (vv. 2711-28)— durante el paso de uno a otro. A estas alturas, la contradícción con lo antes establecido es total y parece irreductible. $Y$, de hecho, no encuentra su solución mientras uno se queda en el circuito cerrado del único texto de la versión madrileña. Sólo con acudir a los textos no oficiales de Valencia y de Zaragoza es como. se logra disipar el misterio. En suss versiones, casi idénticas, de la tercera jomada, vemos que sólo don Luis -y no, sucesivamente don Juan y don Luis, como en el texto madrileño- interviene para interrumpir el sarao secreto, en que se quedan siempre juntos Cosme y Manuel. Estos, con la llegada inesperada de don Luis, se encuentran en la precisión de huir, e Isabel cumple entonces con su acostumbrada función de guía en la oscuridad de la casa-laberinto. Micntras dura el trayecto de los tres hacia el cuarto de Manuel -unos 36 versos, como de costumbre (vv. 314-49)-, Luis lleva a cabo su encuesta policiaca, interrogando con insistencia a su hemana, hasta el nomento en que siente «nido de puertas dentro» (acotacion antes del verso 350). Otra vez es imprescindible transcribir el texto en su casi totalidad: 


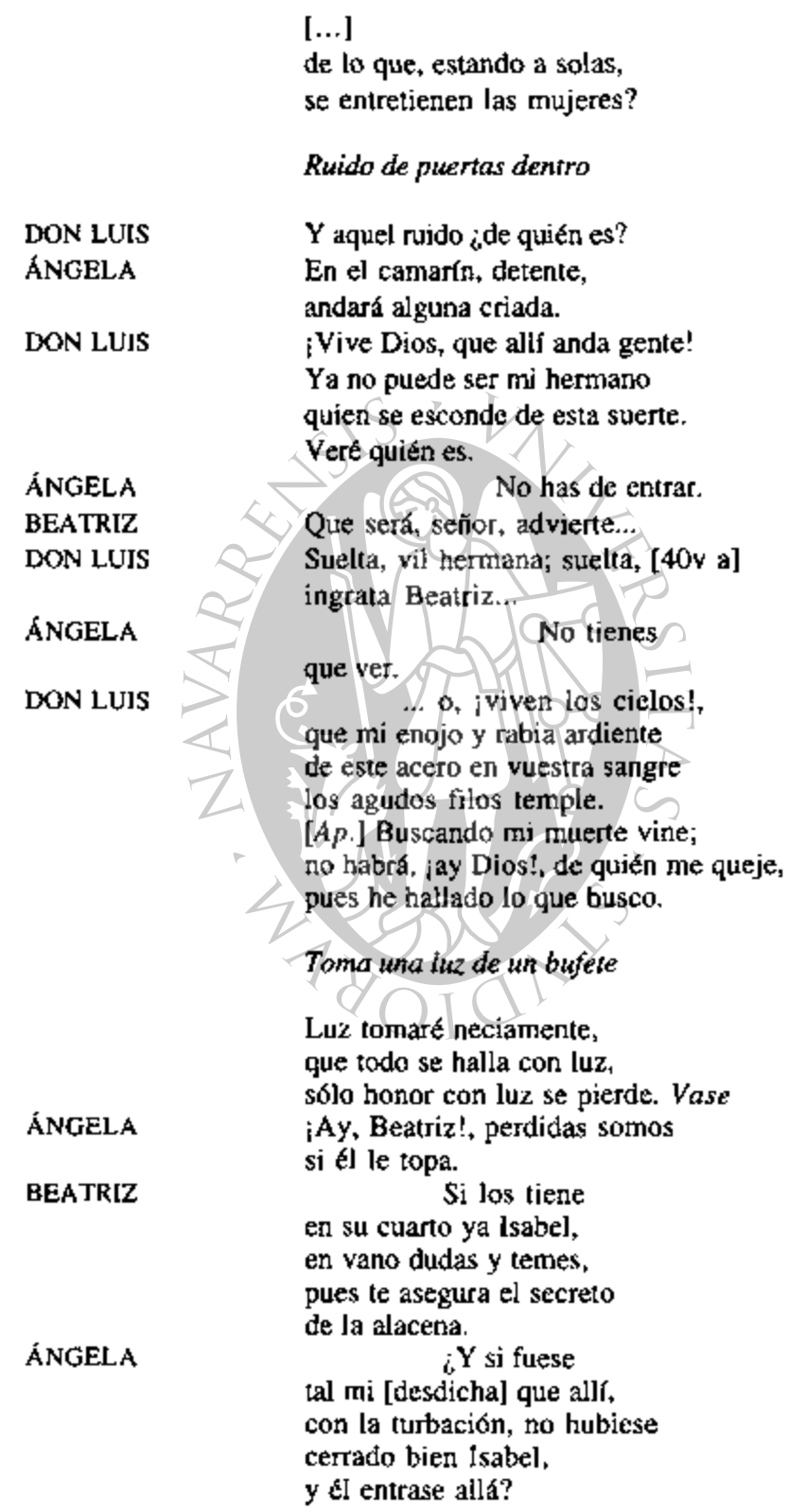


BEATRIZ

ÁNGELA

BEATRLZ

ANGELA
Ponerte

en salvo será importante, si eso por dicha sucede.

Di por desdicha. Beatriz; y si hara, que son crueles mis hados.

¿Y dónde irás?

De tu padre iré a valerme. pues él se valio de mí, porque, trocadas las suertes, si a ti te trujo un pesar a mí otro pesar me lleve.

Vanse. Sale por la alacena don Manuel y Cosme, y Isabel los mete y se va

DON MANUEL Esta cuadra donde cstamos. según a escuras parece, es camarín, porque al ir entrando por una breve $[40 \mathrm{v} b]$ puerta topé con la espada en unos vidrios que liene al entrar.

COSME

DON MANUEI

COSME

DON MANUEL

COSME

DON MANUEL

\section{¡Buenas estamos!}

Oh, a cuánto, cielos, se atreve quien se atreve a entrar en parte donde ni alcanza ni entiende!

¡Qué penas se le aperciben, qué riesgos se te previenen! Veme aquí a ini que, por ser necio, loco y imprudente, estoy ahora en una casa que dueño $\tan$ noble tiene que es Excelencia a lo menos. No es ése el dolor más fuerte, sino el pensar allá fuera que sucede o no sucede de esta mujer.

\section{De las voces}

que se oyen penosamente podras informarte.

\section{Escucha,} que, mal o bien, ya se entiende; y a defenderla la vida saidré, esté donde estuviere. 
Salen don Luis y Isabel con luz

\begin{tabular}{|c|c|}
\hline $\begin{array}{l}\text { DON LUIS } \\
\text { COSME }\end{array}$ & $\begin{array}{l}\text { Yo vi un hombre, ivive Dios } 1 \ldots \\
\text { [AD.] Uno dijo. }\end{array}$ \\
\hline ISABEL & $\begin{array}{l}\text { ¿Como quieres } \\
\text { que se haya ido? }\end{array}$ \\
\hline DON LUIS & ... y he de hallarle. \\
\hline $\begin{array}{l}\text { COSME } \\
\text { DON LUIS }\end{array}$ & [Ap.] Malo es esto. ${ }_{\text {¿Cómo tienes }}$ \\
\hline ISABEL & $\begin{array}{l}\text { desviada esta alacena? } \\
\text { Yo... señor... no sé quién puede } \\
\text { haberla apartado. }\end{array}$ \\
\hline
\end{tabular}

DON LUIS

Quita. (vv. 348-422)

\section{Entran por otra puerta, y salen por la alacena}

El movimiento escénico se desartolla aquí según un proceso perfectamente lógico. Al llegar Isabel, con Cosme y su ano, frente a la puerta interior del cuarto de Manuel, se siente tan qurbada por las circunstancias excepcionales del momento, que fracasa en hacer funcionar silenciosamente el mecanismo de la alacena y forcejea algo con la puerta, con el consigujente rujdo generador de las sospechas intensificadas de Luis. Este «toma una luz de un bufete» $\mathrm{y}$, desde lejos, antes de que Isabel haya podido franquear el paso y disimular a Manuel en su propio cuarto, logra percibir el bulto de un hombre. Poco después, es decir después de la cuarentena de versos de rigor (vv. 370-416, que son 47 versos), se encuentra con Isabel, que ya acaba de meter a sus compañeros en lugar protegido y de salir del mismo, pero con tanta prisa que, confirmando los temores de Ángela (yv. 375-79), no consigue volverlo todo a su orden primero y hacer la deshecha necesaria para engañar a Luis. El segundon de la casa de Toledo con esa agudeza visual que les confieren los celos de honor a los maridos y hermanos calderonianos, repara en la puerta mal cetrada y le pregunta a Isabel cómo puede estar desviada la alacena por fin hallada de su inquisitiva mirada. Ftente al silencio embarazoso de la criada, decide utilizar él mismo el paso de la alacena: para ello tiene que salir con Isabel del escenario ( Entran por otra puerta», antes del verso 423) y dar fuego la ilusión, al volver por la alacena, de que acaba de entrar en el cuarto de Manuel, en que se reanuda - primer momento del desenlace- el duelo internumpido en los primeros momentos de la comedia. 
Un solo vistazo sobre la versíon madrileña de esta misma escena basta para percatarse de que se trata de una refundición bastante inhábil hecba por un Calderón algo olvidadizo de las intenciones de su primera empresa. Porque aquí se impone una nueva evidencia: el texto de Valencia-Zaragoza, por el implacable rigor de la construcción dramática y escénica del pasaje estudiado, no puede ser sino la primera redacción -y ésta no atribuible sino al propio Calderón- de la tercera jomada de La dama duende.

Frente a ella, la versión madrileña de la escena considerada aparece como un trabajo de reescritura exigido, a expensas de la coherencia interna, por las necesidades globales de la reelaboración de conjunto del tercer acto, emprendida con vistas a la integración de la obra en la edición oficial de la Primera parte.

Que sea esta práctica nada infrecuente en Calderón se demostraría fácilmente, con sólo mencionar el caso - aplicable esta vez al conjunto de las tres jomadas- de La vida es sueño y de su versión de Zaragoza, tan diferente, a pesar de la fecha idéntica de su publicación (1936), de la oficial y universalmente conocida de Madrid'. Pero de mayor interés para el aspecto limitado que hoy nos ocupa será el examen de algunos detalles del texto madrileño recién citado, y particulamente de tos cuatro empleos de la palabra alacena. No ofrece la menor dificultad la intelección de las dos ocurrencias que se dan en el texto principal _el pronunciado por los personajes- en los versos 2716 y 2731: remiten ambas al cspacio dramático, es decir al de la ficción, confumando la primera, en boca de Beatriz, la existencia efectiva, entre los dos cuartos, de un intervalo espacial considerable, cuya presencia subrayamos repetidamente. En cambio, las dos apariciones del vocablo alacena en el texto secundario de las acotaciones que preceden a los versos 2699 y 2703 no se pueden entender si no se da un salto mental desde el espacio dramático hasta el espacio escénico, según la precisa definición que de estas nociones propusimos al empezar.

Cuando escribe Całderón que Isabel y Cosme «hacen ruido en la alacena», cuando añade que Luis aparta la misma alacena «para entrar con luz», no puede, ya que la escena se sitúa en cl cuarto de Ángela, aludir con estas frases a un elemento de un espacio dranático del que sabemos a ciencia cierta que se ubica en el cuarto de Manuel. Lo que sí hace, dirigiéndose directamente al «autor" o a los actores, es designales la parte trasera del teatro, es decir del

7 Véase nuestro libro sobre Segismando et Serafina. Toulouse, France-iberie Recherche, 1980, p. 7, n. 3. 
espacio escénico, en que se encuentra, desde el principio hasta el final de la representacion, la alacena practicabic construida por los representantes, o sea la alacena en cuanto objeto efectivamente fabricado para uno u otro de los corrales madrileños de los años de 1630 .

De ella tenemos una descripción técnica - hecho lo bastante excepcional como para merecer toda nuestra atención- en la acotación que precede al verso 781, es decir en el momento de su primera utilización concreta por los actores, que es, también, el momento de su primera aparición a los ojos de los espectadores: «Por una alacena que estard hecha con anaqueles y vidrios en ella, quitándose con goznes, como que se desencaja, salen...».

He aquí la reducción escénica de la complejísima alacena dramática, que Isabel nos describía con tanto tujo de detalles, con su carácter portátil, sus dos clavos puestos en falso y su delicadísimo manejo «para que solo la sepa abrir / el que lo llega a saber» (vv, 615-6), y también para que se pueda usar «sín ser posible que se eche $/$ de ver" $(\gamma v, 794-5)$. He aquí, también, en el texto nuevamente escrito para la Primera parte, y como sin quererlo, uлa preciosa información sobre la ubicación exacta de esta alacena escénica en el tablado de un corral aureo, ubicación que podemos hoy imaginar gracias a las reconstrucciones llevadas a cabo por los historiadores del teatro, y que va pormenorizando con toda puntualidad J. E. Varey en su citada conferencia del Congreso Calderón de 1981:

El tablado escénico saliente estaba rodeado en sus tres lados por los espectadores. El fondo del tablado estaba provisto de cortinas, y las entradas y salidas se hacían por lo general por dos aberturas en estas cortinas a los dos extremos del fondo

[..] Entre estas dos puertas habia un espacio que se podía revelar por medio de correrse las cortinas. Este espacio tenfa su equivalente en la escena inglesa de la época, y los estudiosos del teatro de Isabel I solían llamarlo la escena interior

[...] A veces esta escena interior [...] simulaba en el corral de comedias español una cueva, gruta, cárcel o torre, y en otras ocasiones se utilizaba para hacer entrar en el tablado muebles y otros accesorios escénicos. Creo que en $L a$ dama dhende la alacena fue erigida detrás de las cortinas de esta escena interior, y que se revelaba sólo en aquellos cuadros donde la acción pasaba en el cuarto de don Manuel 
[...] Debŕa haberse construido dentro de un marco, a poca distancia detrás de las cortinas que cubrían normalmente el fondo del tablado escénico. Al correrse las cortinas, se dejaría a la vista del auditorio; cuando el tablado representaba otro cuarto que el de don Manuel, us otro sitjo cualquiera, sólo era necesario cerrar otra vez las cortinas para que no se viese

La confusión gencrada por la desorientadora refundición mađrileña se desvanece ahora. No pasan las cosas como lo cree el crítico británico, cuando, al tratar de explicar las enigmáticas acotaciones de la Primera parte, escribc:

Buscando el origen del ruido, [Luis] descubre la alacena: es ésta la primera y única ocasión en que el público ve la alacena desde el lado del cuarto de doña Ángela, aunque es posible que dan Luis solo aparte las cortinas: Aparta la alacena, dice la acotación (acor. 2703)

y cuando, despućs de citar las observaciones de Beatriz (vv. 2712-16), añade:

Don Luis, pues, no ha adivinado el secreto de ia alacena, y habra entrado por una de las puertas laterales (ant. cil. p. 180)

No. Para salir del escenario. Luis no escoge una de las puertas laterales escénicas, que tíguraría una de las posibles salidas de la compleja unidad dramática llamada cuarto de doña Ángela. Lo que hace, en cambio, es pasar por el espacio escénico central, en que sigue siłuándose la alacena escénica -no visible para los espectaderes, por estar apartada por el actor que hace de Luis- y que, en este punto preciso del desarrollo de la acción, sirve para representar otra salida del cuarto de Ángela, posiblemente la que conduce al "camarín» mencionado por las versiones de Valencia y de Zaragoza (v. 351).

En realidad, nos encontramos aquí con un ejemplo particularmente revelador de la naturaleza exacta de los condicionamientos escenográficos de los corrales del Siglo de Oro. Su rasgo más característico reside en la enorme distancia que puede existir entre la complejidad teónicamente ilimitada de las unidades del espacio oramático - $-\mathrm{y}$ dc sus interrelaciones- y la sencillez exirema, por no decir escasez o pobreza, de los componentes del espacio escénico. La mediación entre las dos instancias corre a cargo, como es sabido, de lo que a veces se llama el decorado verbal o hablado , que convienc

8 Ver Patrice Pavis, op. cit., pp. 101 y 216: y taubién Frédéric Serralta, el capitulo [V («El icatro en el siglo XVII», escrito en colaboración con Marc Vitse, Javier Huerta Calvo y 
completar con la función de los movimientos escénicos destinados a traducir el paso, a veces progresivo, de una a otra de las unidades del espacio dramático. No recordaremos aquí, por ser fenómeno ya bien estudiado, sino un solo ejemplo sacado del pasajc anteriormente copiado de las versiones no of iciales.

Isabel, como ya vimos, acaba de meter a Manuel y Cosme en el cuarto de aquél, por la acostumbrada vía de la alacena. Se marcha, y deja solos a amo y criado, que se interogan sobre la naturaleza exacta del aposento en que se encuentran. De súbito, oyen unas voces, y deciden esperar en la oscuridad para ver lo que va a ocurrir, retirándose, con toda probabilidad a un lado del escenario. Entonces es cuando salen al mismo escenario, por una de las puertas escénicas, Luis e Isabel, acabada ésta de ser alcanzada por Luis e interrogada por él con cierta violencia, con vistas a identificar el bulto que sólo pudo entrever. En este momento, el mismo espacio escénico -el tablado del corral en su conjunto- representa simultáneamente el interior del cuarto de Manuel (en un lado), la alacena entrcabierta que vislumbra Luis (en el centro), y parte del paso secrcto que conduce del cuarto de Ángela al de Manuel, y en que se hallan hablando Luis e Isabel (en otro lado).

Se trata, en definitiva, de una adaplación áurea de la ya antigua tćcnica de los escenarios múltiples, que se complementa aquí, para responder a la necesidad dramática, con la función antes mencionada del desplazamiento físico de los actores como signo del transcurso de los personajes de una unidad espacial a otra. Así es como Luis e Isabel, por el mero hecho de entrar primero por una puerta diferente de la de su inicial salida al escenario, y lucgo de salir de nucvo a él por la alacena, abandonan el espacio dramático del paso secreto para encontrarsc posteriormente en el cuarto de Manucl, cn que chocan con el huesped, y después con su criado.

A decir verdad, no hay en esto nada verdaderamente nuevo, aunque si se da - propia de la condensación espacial característica del sistema calderoniano de la comedia de capa y espada - una explotación máxima de la ductilidad infinita del espacio escénico, de por sí neutro, de los corrales áureos.

Jose María Diez Borque) de la Historia del tearo en Espoña. J, Edad Media, Siglo XVl, Siglo XVIL, dirigida por J. M' Díez Borque, Madrid, Taurus, 1984, pp. 652-53. 
No parece que se hayan considerado con suficiente atencion todas las implicaciones de esta plasticidad sin limites de los cscenarios casi vacíos del Sigfo de Oro, de esa plasticidad ofrecida, con la aportación de los signos verbales y cinéticos emitidos por los personajes, al poder imaginativo de unos oyentes siempre solicitados. Por eso es por lo que quisiéramos terminar haciendo algunas observaciones sobre lo que podría llamarse, quizá con alguna impropiedad, el «espacio textual», o sea la disposición estructural de la comedia en cuanto organización textual.

Si alguna veracidad se otorga al análisis que acabamos de hacer de la supremacía, para la identificación de los espacios, no del lenguaje escénico (los tan escasos signos del decorado o del espacio escénico), sino del lenguaje dramático (los pletóricos signos emitidos por los personajes en sus parlamentos y en sus andanzas por el escenario), si esta jerarquización de los medios informativos constituye, pues, bajo esta forma, tina especificidad fundamental del sistema teatral áureo. entonces se impone cono su consecuencia ineludible la incapacidad de los cambios de lugar para servir de elementos estructurantes u organizadores del desarrollo dramático de una comedia.

El ejemplo de la reelaboración del texio calderoniano que, a este respecto, emprendio, hace más de un siglo, el editor J. E. Hartzenbusch, permitirá concretar con mayor claridad el principio negativo que acabamos de enunciar.

Sabido es que, en su edición preparada para la BAE (tomo VII, pp. 167186), el insigne calderonista trató de imponer a los textos de Calderón todo un sistema de découpage 0 de diyision en cuadros y escenas, sistema sacado por lo esencial de los cánones del teatro francés clásico y neoclásico y fundado sobre el cambio de lugar como criterio definidor de los cortes entre las varias unidades dramáticas.

En lo que a La dama duende se refiere, llegó a la repartición que se lee en la columna izquierda del cuadro siguiente, y que J. E. Varey acepta en su integralidad para elaborar su propio análisis:

\begin{tabular}{lll} 
HARTZENBUSCH/ & SINOPSIS DE & REPARTICIÓN \\
VAREY & VERSIFICACIÓN & PROPUESTA \\
\hline & JORNADA PRIMERA
\end{tabular}
A - Calle
1-368: romance $\hat{e}-a$
$A^{\prime}-$ [Caile]
B - Habitación de
369-652: redondillas Ángela
B'- [Cuarto de Ángela o sala en casa de Don Juan]




\begin{tabular}{|c|c|c|}
\hline \multirow[t]{3}{*}{ C - Cuarto de Manuel } & $\begin{array}{c}\text { 653-780: silva de } \\
\text { pareados }\end{array}$ & $\begin{array}{c}\left.\mathrm{C}^{\prime} \text { - [Cuarto de Manuel }\right] \\
\text { 1-Llegada y salida de } \\
\text { Cosme }\end{array}$ \\
\hline & 781-1002: romance é-e & $\begin{array}{l}\text { 2-Hasta la lectura de la } \\
\text { carta }\end{array}$ \\
\hline & 1003-1102: redondillas & $\begin{array}{l}\text { 3-Despues de la lectura } \\
\text { de la carta }\end{array}$ \\
\hline
\end{tabular}

\section{JORNADA SEGUNDA}

D - Habitación de 1103-1310; rom. $\hat{a}-e \quad D^{\prime}$ - [Sala en casa de Don Ángela 1311-1410: décimas Juan] 1411-1530: redondillas

E - Cuarto de Manuel 1531-1730: rom. $\hat{e}-o$

E' - [Cuarto de Manuel]

(con estribillo de cantar popular, 1569-1572)

F - Cuarto de Ángela 173]-1888; silva de F - [Sala en casa de Juan] paraados 1889-1916: sonetos

G - Calle (1917-1984) 1917-2028: redondillas $G^{\prime}$ - [Espacio Manuel] 1-Antes de la luz de Ángela

H - Cuaro de Manuel 2029-2242: romance é 2-Después de la luz (1984-2242)

JORNADA TERCERA

I - Cuarto de Ángela 2243-2292: quintillas H' - 1-Antes de hablar (2243-2478)

J - Cuarto de Manuel 2293-2422: décimas (2479-2592) 2423-2592; rom, é-e Ángela

$\mathrm{K}$ - Sala de Ángela 2593-2672: quintillas (2593-2726) 2673-2910: rom. é-e 2-Diálogo con Ángela 3-Llegada de Juan L - Cuarto de Manuel (2727-3114)

2911-3034: silva de pareados 3035-31 14; rom. á-a r' - 1-Ángela y Cosme 2-Llegada de Luis J' - 1-Manuel y Ángela 2-Descnlace

(No hay repartición topográfica compatible con los cortes métricos). 
Cono se ve, para el editor del siglo XiX son doce los cuadros o núcleos escénicos que componen La dama duende, y estos núcleos se distribuyen entre tres unidades espaciales, que son la calle $(A, G)$, el cuarto, o habitación, o sala de Ángela (B, D, F, I, K) y el cuarto de Manuel (C, E, H, J, L).

Esta división, al parecer inatacable, no tarda sin embargo en revelarse inadecuada, porque choca violentamente con otro principio de repartición del movimiento propiamente dramático, el de la ordenación del «espacio textual» según las coordenadas proporcionadas por Ia polimetría. Son tres las veces en que la división espacial decimonónica se entrenta con las indicaciones de ta división métrica áurea. Los cortes establecidos por Hartzenbusch entre los versos 1984 y 1985,2478 y 2479 , y, finalmente, 2726 y 2727 , entran en abierta contradiccion con el desarollo de unas series continuas de redondillas, primero, (vv. 1917-2028) y, luego, de versos romances asonantados en é o $e$ $e$ (vv. 2423-2592 y $\mathrm{\gamma v}, 2673-2910$ ). $\mathrm{Nj}$ que decirse tiene que, en este conflicto entre dos sistemas incompatibles de repartición escénica, la preferencia ha de darse al original calderoniano, el cual, cuando mirado con atguna detención. se revela en perfecta concordancia con los diversos momentos de la evolución dramática, es decir con las varias etapas de un proceso teatral ordenado no según el espacio sino según el tiempo dramático. Es lo que puede verse en la nueva repartición que proponemos en la columna situada a la derecha de la sinopsis de versificación del cuadro ya mencionado. Allí figuran los diez núcleos escénicos ideados por Calderón para trazar la trayectoria de su héroe, Manuel, en su investigación sistemática para descubrir el enigma que ofrecen a su valor las burlas de Ángela. Para su delimitación, tanto en lo que concieme al conjunto de los diez núcleos como en lo que se refiere a las subdivisiones de cada uno de ellos, impera la polimetría, instrumento insustituible para marcar el ritmo - hasta podría decirse la puntuacion- de la frase dramática que constituye, metafóricamente, toda dramatización. Así, en el núcleo escénico G', centrado dramáticamente en el personaje de Manuel: el paso de la serie de redondillas al romance no corresponde con el paso de la calle al interior del cuarto del protagonista; muy al contrario, estos dos espacios dramáticos (calle y cuarto), casi idénticos en su representación escénica (con el solo cambio de la cortina corrida para descubrir la (escena interior») no son más, en la realidad del movimiento profundo de la obra, que la parte exterior y la parte interior de una unidad espacial temporalmente única, y que podríamos llamar el «espacio Manuel». El cambio métrico entre los versos 2028 y 2029 aparece entonces con su plena función de revelador del momento clave de la evolución dramática 
inscrita en el «espacio Manuel»: el que presencia no la entrada física de Ángela en este espacio (cosa que se dio ya en el verso 1985), sino su aparición como ángel de luz propuesto a la valerosa sagacidad del caballero deslumbrado.

Es inútil seguir la demostración, cuyas conclusiones aparecen figuradas esquemáticamente en los subtítulos que propusimos para los núcleos de ta tercera jornada $\left(\mathrm{H}^{\prime}, \mathbf{I}^{\prime}\right.$ y J'). En esta, la imposibilidad de establecer cualquier correspondencia entre los cortes métricos y la repartición topográfica de los espacios dramáticos no permite solamente darse plena cuenta de la aceleración rítmica de un acto constituido por un permanente, y admirablemente ordenado, vaivén entre el «espacio Manuel» y el «espacio Ángela». Autoriza, también, y sobre todo, esta conclusión, que creemos valedera para la gran mayoráa de la producción teatral áurea: y es que no en el espacio -ampliamente abiento, a partir de la escase $z$ escenica, a la imaginativa de los oyentes - sino en el tiempo reside el principio de ordenacion primigenio de la Comedia, la cual encuentra co esta su organización preferentemente temporal, una de las condiciones de su actual vigencia estética.

Recapitulemos:

- necesidad de una labor filológica que ponga por fin a nuestra disposición un texto fidedigno que garantice la veracidad de futuras investigaciones propiamente literarias

- utilidad, al lado de los métodos clásicos de establecimiento textual, de unas bases terricas sobre las especificidades del texto teatral, como son las nociones de espacio dramático y espacio escénico, etc.

- y, por fin, - y muchas veces a contrapelo de las reducciones ofuscadotas de los críticos decimononicos y de sus secuaces - respeto de los principios informantes de la estética teatral del Sigio de Oro.

Tales son las observaciones metodológicas que merecen tenerse en cuenta a la hora de abordar un texto tan conocido, por lo menos en apariencia, cono La dama ditende. Sírvannos, de rechazo, para escarmentar y aproximarnos con la debida humildad a cualquier otro texto de la terra aún tan incógnita del mundo teatral del Siglo de Oro. 